\title{
EVALUASI PROGRAM PENYULUHAN USAHA PETERNAKAN SAPI DI KECAMATAN SINONSAYANG KABUPATEN MINAHASA SELATAN
}

\author{
Nissa Sajow*, B.F.J. Sondakh**, R.A.J. Legrans**，J. Lainawa** \\ Fakultas Peternakan, Universitas Sam Ratulangi Manado 95115
}

\begin{abstract}
ABSTRAK
Kecamatan

sinonsayang

merupakan salah satu Kecamatan yang terletak di wilayah Kabupaten Minahasa Selatan yang terdiri dari 13 desa dan memiliki luas wilayah $12.960 \mathrm{Ha}$. Umumnya masyarakat Sinonsayang berprofesi sebagai petani/peternak. Populasi ternak sapi terbanyak di Kecamatan Sinonsayang terdapat di 3 desa antara lain Desa Blongko, Desa Ongkaw II dan Desa Ongkaw III adalah sebanyak 296 ekor. Adapun masalah penelitian ini adalah sejauh mana keberhasilan program penyuluhan BP3K dalam hal peningkatan populasi ternak sapi di Kecamatan Sinonsayang Kabupaten Minahasa Selatan. Tujuan penelitian ini adalah mengevaluasi pelaksanaan kegiatan penyuluhan di Kecamatan Sinonsayang Kabupaten Minahasa Selatan. Penelitian ini dilaksanakan dengan menggunakan metode survey. Penentuan desa sampel secara purposive sampling, yaitu menetapakan 3 desa yang memiliki populasi ternak sapi terbanyak. Responden adalah petani peternak yang ditetapkan secara random sebanyak 30 orang (responden). Data dalam penelitian ini diperoleh dari 2 sumber yaitu data primer dan data sekunder. Hasil dalam penelitian ini menunjukkan bahwa penyuluhan yang dilakukan oleh BP3K belum berhasil dan juga tidak efektif, karena kegiatan penyuluhan hanya dapat menjangkau sebagian kecil
\end{abstract}

\footnotetext{
*Alimni Fakultas Peternakan Unsrat **Jurusan Sosial Ekonomi Peternakan
}

dari jumlah peternak. Hal ini yang menyebabkan banyak peternak kurang motivasi berusaha akibatnya populasi ternak sapi kurang berkembang.

Kata Kunci : Evaluasi, Penyuluhan, Peternakan Sapi

\section{ABSTRACT}

\section{EXTENSION \\ PROGRAM \\ EVALUATION IN CATTLE \\ FARM BUSINESS AROUND \\ INONSAYANG DISTRICT, SOUTH MINAHASA REGENCY.}

Sinonsayang district is located in the regency of South Minahasa consisted of 13 villages and area size of 12,960 ha. Generally, Sinonsayang communities were living as farmers / ranchers. The highest populations of cattle were focused in 3 villages around Sinonsayang district including Blongko Village, Ongkaw II and III Villages (296 cattle). The problem of this study was how far the success of extension program in terms of improving education of BP3K for cattle population in the district of Sinonsayang, South Minahasa Regency. The objective of this study was to evaluate the implementation of extension activities around Sinonsayang district, South Minahasa regency. The research was conducted in January to February, 2014 using survey method at the 3 sampling villages with the highest cattle population. The respondents were farmers and ranchers who were randomly targeted for outreach assigned to 30 people (respondents). Research and data collection were done during 2 months. The data in this study were obtained from two sources (primary data 
and secondary data). Method of purposive sampling was done intentionally. The use of this technique was based on certain characteristics obtained through the population. The results in this study indicated that the extension was not successfully and effectively done by BP3K, because the extension service can only reach few numbers of breeders. Therefore more farmers had less motivation to breed their cattle population.

Keywords: Evaluation, Extension, Livestock Cattle

\section{PENDAHULUAN}

Kecamatan Sinonsayang adalah salah satu kecamatan di Kabupaten Minahasa Selatan Propinsi Sulawesi Utara yang memiliki potensi pengembangan usaha peternakan sapi potong. Hasil prasurvey menunjukkan bahwa di daerah tersebut sudah pernah dilakukan berbagai kegiatan penyuluhan tentang pengembangan usaha peternakan sapi potong, baik yang dilakukan oleh instansi pemerintah daerah maupun dari berbagai lembaga lainnya.

Menurut laporan Balai Penyuluhan Pertanian Perikanan Peternakan dan Kehutanan (BP3K) Kecamatan Sinonsayang Kabupaten Minahasa Selatan Tahun 2013, permasalahan dilakukannya kegiatan penyuluhan karena perkembangan populasi ternak sapi di daerah tersebut tidak mengalami peningkatan. Lambatnya peningkatan tersebut dinilai akibat dari kegagalan reproduksi dan penanganan kesehatan ternak atas dasar tersebut maka BP3K melakukan penyuluhan peternakan sapi tentang reproduksi ternak sapi dan penanganan kesehatan hewan. Penyuluhan tersebut dilaksanakan didesa Blongko, desa Ongkaw II dan desa Ongkaw III pada bulan Agustus 2013 dengan sumber dana APBN dan APBD, tujuan utama penyuluhan tersebut adalah meningkatkan populasi ternak sapi untuk mencapai swasembada daging. Sasaran penyuluhan BP3K adalah untuk meningkatkan populasi ternak sapi dari jumlah 1.071 ekor menjadi 1.500 ekor.

Program penyuluhan yang direncanakan, perlu dievaluasi apakah telah dilaksanakan sesuai dengan rencana penyuluhan. Dalam hal ini, proses penyuluhan, aspek teknis, metode, materi dan petugas penyuluhan akan berpengaruh terhadap efektivitas penyuluhan. Adapun masalah penelitian ini adalah sejauh mana keberhasilan program penyuluhan BP3K dalam hal 
peningkatan populasi ternak sapi di Kecamatan Sinonsayang. Tujuan penelitian ini adalah mengevaluasi pelaksanaan kegiatan penyuluhan di Kecamatan Sinonsayang Kabupaten Minahasa Selatan.

\section{MATERI DAN METODE PENELITIAN}

Penelitian ini telah dilaksanakan di desa Blongko, desa Ongkaw II dan desa Ongkaw III Kecamatan Sinonsayang Kabupaten Minahasa Selatan. Pengambilan sampel dilakukan secara purposive dengan memilih 3 desa dari 13 desa yang ada di kecamatan Sinonsayang Kabupaten Minahasa Selatan, masing-masing adalah desa desa Blongko, desa Ongkaw II dan desa Ongkaw III. Menurut hasil prasurvey, dari 13 desa yang ada di kecamatan Sinonsayang Kabupaten Minahasa Selatan, hanya 3 desa tersebut yang pernah dilakukan penyuluhan peternakan sapi oleh Balai Penyuluhan Pertanian Perikanan Peternakan dan Kehutanan (BP3K). Responden adalah peternak dan petugas penyuluhan. Responden peternak sebanyak 30 orang dan responden petugas penyuluhan adalah penyuluh peternakan serta staf BP3K Kecamatan Sinonsayang.

Data sekunder diperoleh dari Dinas Pertanian Kabupaten Minahasa Selatan dan kantor Balai Pusat Statistik (BPS) Propinsi Sulawesi Utara. Adapun variabelvariabel dari data sekunder ini adalah luas lahan, populasi ternak sapi, serta populasi semua jenis ternak dan jumlah penduduk.

Analisis data yang digunakan dalam penelitian ini yaitu deskriptif kualitatif dengan tahap pertama melakukan pemeriksaan data, pada kegiatan ini dilakukan setelah melakukan wawancara (mengisi daftar pertanyaan). Analisis deskriptif dapat diartikan sebagai prosedur pemecahan masalah yang diselidiki dengan menggambarkan atau mendeskripsikan keadaan subjek/objek penelitian berdasarkan fakta-fakta yang tampak atau sebagaimana adanya (Nawawi, 1995).

\section{HASIL DAN PEMBAHASAN}

Karakteristik responden yang dibahas dalam penelitian ini menyangkut umur, pendidikan, pekerjaan, dan jumlah anggota keluarga merupakan faktor-faktor 
yang turut memberikan pengaruh dalam pemeliharaan ternak sapi di Kecamatan Sinonsayang. Berdasarkan hasil penelitian diperoleh bahwa, jumlah tanggungan keluarga responden bervariasi dari 26 orang jumlah tanggungan per keluarga. Hal ini berarti rata-rata jumlah tanggungan sebanyak 4,13 orang per keluarga responden. Berdasarkan beberapa hasil penelitian menunjukkan bahwa, jumlah anggota keluarga mempengaruhi tingkat pengeluaran rumah tangga peternak. Semakin banyak jumlah anggota tanggungan suatu keluarga peternak akan turut mempengaruhi jumlah pengeluaran rumah tangga (Elly dan Salendu, 2012). Hasil penelitian menunjukkan bahwa rata-rata jumlah anggota keluarga sebesar 4,13 orang. Jumlah anggota keluarga ini mempengaruhi pengeluaran khususnya tingkat konsumsi rumah tangga.

Hasil penelitian diperoleh bahwa, tingkat pendidikan kelompok tani peternak sapi sebagai responden dikategorikan cukup rendah karena sebagian besar masih berada pada tingkat pendidikan SMP sebesar $43,33 \%$ responden berpendidikan SD sebesar $30 \%$, dan terdapat responden berpendidikan SMA sebesar 20\%, dan hanya $6,67 \%$ responden yang berpendidikan Perguruan Tinggi.

Berdasarkan hasil penelitian, sebagian besar responden berprofesi utama sebagai petani ternak sapi yaitu sebesar 86,67\%. Adapun responden yang berprofesi sebagai guru yaitu 3,33\%, tukang 3,33\% dan pedagang sebesar $6,67 \%$. Berdasarkan wawancara dengan responden bahwa walaupun pekerjaan utamanya adalah pedagang tapi juga memelihara sapi. Pemeliharaan ternak sapi merupakan usaha sampingan yang diperlukan untuk menambah penghasilan keluarga. Ternak sapi sebagai aset yang sewaktu-waktu dapat dijual apabila kebutuhan mendesak.

Balai Penyuluhan Pertanian Perikanan Peternakan dan Kehutanan (BP3K) Kecamatan Sinonsayang Kabupaten Minahasa Selatan dibentuk pada tahun 2004 oleh Badan Pelaksana Penyuluhan Pertanian Perikanan Peternakan dan Kehutanan (BP4K) Kabupaten Minahasa Selatan. Secara Hirarki BP3K Kecamatan Sinonsayang berada dibawah Departemen 
Tabel 1. Frekuensi Penyuluhan Yang Diikuti Peternak di Kecamatan Sinonsayang

\begin{tabular}{llllll}
\hline \multicolumn{2}{c}{ Penyuluhan Perorangan } & \multicolumn{3}{c}{ Penyuluhan Kelompok } \\
\hline $\begin{array}{l}\text { Penyuluhan } \\
\text { perorangan } \\
\text { (banyaknya } \\
\text { pertemuan) }\end{array}$ & $\begin{array}{l}\text { Peserta } \\
\text { penyuluhan } \\
\text { perorangan } \\
\text { (Org) }\end{array}$ & $(\%)$ & $\begin{array}{l}\text { Penyuluhan } \\
\text { Kelompok } \\
\text { (banyaknya } \\
\text { pertemuan) }\end{array}$ & $\begin{array}{l}\text { Peserta } \\
\text { penyuluha } \\
\text { n } \\
\text { Kelompok }\end{array}$ & $(\%)$ \\
\hline $0-1$ & 6 & 20 & $0-1$ & 8 & 6,66 \\
$2-3$ & 24 & 80 & $2-3$ & 22 & 73,33 \\
\hline Jmlh & 30 & 100 & & 30 & 100 \\
\hline
\end{tabular}

Pertanian dan BP4K Kabupaten

Minahasa Selatan. Seluruh anggaran

kegiatan Balai Penyuluhan Pertanian

Perikanan Peternakan dan Kehutanan

BP3K Kecamatan Sinonsayang berasal dari BP4K Kabupaten Minahasa Selatan.

Berdasarkan Undang-undang Nomor 16 Tahun 2006, tentang Sistem Penyuluhan, Pertanian, Perikanan, Peternakan dan Kehutanan mengamanatkan bahwa kelembagaan penyuluhan pertanian perikanan peternakan dan kehutanan terdiri dari kelembagaan penyuluhan pemerintah dan kelembagaan penyuluhan.

$$
\text { Program penyuluhan }
$$

peternakan sapi yang dilakukan oleh

Balai penyuluhan Pertanian,

Peternakan, Perikanan, dan

Kehutanan (BP3K) Kecamatan

Sinonsayang Kabupaten Minahasa
Selatan, dilaksanakan dalam rangka menumbuhkembangkan keberdayaan swadaya dan peran serta pelaku atau para peternak sapi agar dapat meningkatkan produktifitas pendapatan usaha peternakannya. Dalam rangka meningkatkan ketrampilan beternak baik kepada peternak maupun kepada petugas penyuluhan sehingga terjadi penumbuhan pemberdayaan dan kemadirian. Tujuan khusus adalah meningkatkan populasi dan pemahaman tentang kesehatan ternak.

Rencana kerja penyuluh atau rencana definitif disusun berdasarkan kebutuhan yang dirasakan petani/peternak, Sebelum menyusun rencana kerja penyuluh, BP3K Kecamatan Sinonsayang melakukan identifikasi potensi wilayah terlebih dahulu. Potensi tersebut termasuk 
potensi SDM dan SDA wilayah tersebut. SDM yaitu meliputi penyuluh dan petani di wilayah tersebut. Sedangkan SDA meliputi keadaan tanah,sistem pengairan, dan komoditi pertanian temasuk komoditi peternakan sapi potong apa yang cocok dikembangkan di wilayah kecamatan Sinonsayang. Rencana kerja disusun setiap tahunnya, dan dibuat dalam bentuk tertulis, dimana petani/peternak tidak diperlihatkan rencana kerja tertulis tersebut, karena penyuluh akan langsung memberikan praktek rencana kerja tersebut kepada petani/peternak.

BP3K

Kecamatan

Sinonsayang bekerja melakukan penyuluhan pertanian pada hari senin, selasa, kamis dan jumat. Khusus untuk penyuluhan peternakan sapi potong dijadwalkan pada hari jumat dengan frekuensi penyuluhan untuk perorangan ratarata 1 kali dalam satu bulan, atau disesuaikan dengan kebutuhan, dan pernah dilakukan 2 sampai 3 kali dalam sebulan. Sedangkan untuk penyuluhan kelompok, pada tahun 2013 telah dilakukan 4 kali penyuluhan terhadap 3 kelompok peternak petani yaitu gabungan kelompok tani "Kamangta" di desa Blongko, gabungan kelompok tani "Prima" di desa Ongkaw II dan gabungan kelompok tani "Boga Jaya" di desa Ongkaw III.

Materi penyuluhan yang disampaiakan oleh BP3K disesuaikan dengan mempertimbangkan permasalahan petani/peternak yang dihadapi saat itu. Materi penyuluhan peternakan sapi yang telah dilakukan BP3K Kecamatan Sinonsayang pada tahun 2013 yaitu mencakup reproduksi dan penanganan kesehatan ternak sapi.

Menurut Effendy materi atau pesan yang disampaikan kepada sasaran hendaknya disesuaikan dengan kebutuhan dari individu keluarga kelompok dan masyarakat sehingga materi yang disampaikan dapat dirasakan langsung manfaatnya. Materi yang disampaikan sebaiknya menggunakan bahasa yang mudah dimengerti, tidak terlalu sulit untuk dimengerti oleh sasaran, dalam penyampaian materi sebaiknya menggunakan metode dan alat bantu untuk mempermudah pemahaman dan untuk menarik perhatian sasaran. 
BP3K melakukan kegiatan penyuluhan kepada petani/peternak pada tempat-tempat tertentu yaitu dibalai desa atau rumah penduduk, dan lahan usahatani. Selama kegiatan penyuluhan sebagian besar petani/peternak sapi potong peserta penyuluhan sudah berkumpul terlebih dahulu sebelum penyuluh BP3K tiba ditempat, para peserta penyuluhan dikoordinir langsung oleh ketua kelompok tani maupun aparat desa.

Materi penyuluhan disampaikan tidak dengan menggunakan alat bantu penyuluhan pengeras suara, LCD, video/film. melainkan hanya menggunakan suara langsung penyuluh. BP3K juga memberi keleluasan kepada petani/peternak meminta topik materi tertentu apa saja yang menjadi permasalahan mereka untuk disuluhkan oleh penyuluh BP3K Kecamatan Sinonsayang. Kegiatan penyuluhan yang dilakukan oleh penyuluh BP3K selama tahun 2013 tidak menggunakan alat peraga/sampel, sehingga hasil evaluasi BP3K kegiatan penyuluhan yang mereka lakukan hanya bisa dimengerti oleh sebagian petani dan hanya ditindak lanjuti oleh sebagian dari petani yang telah mengerti tadi.

$$
\text { Menurut Notoatmodjo }
$$
(2007), alat bantu penyuluhan adalah alat-alat yang digunakan oleh penyuluh dalam menyampaikan informasi contohnya berupa LCD, vidio/film serta pengeras suara. Sedangkan, alat peraga berfungsi untuk membantu dan meragakan sesuatu dalam proses penyuluhan contoh alat peraga berupa sampel. Alat peraga ini disusun berdasarkan prinsip bahwa pengetahuan yang ada pada setiap manusia itu diterima atau ditangkap melalui panca indera. Semakin banyak indera yang digunakan untuk menerima sesuatu maka semakin banyak dan semakin jelas pula pengertian/pengetahuan yang diperoleh, dengan kata lain, alat peraga ini dimaksudkan untuk mengerahkan indera sebanyak mungkin kepada suatu objek sehingga mempermudah persepsi.

$$
\text { Menurut Notoatmodjo }
$$
(2007), secara terperinci, fungsi alat peraga adalah untuk menimbulkan minat sasaran, mencapai sasaran yang lebih banyak, membantu mengatasi hambatan bahasa, merangsang sasaran untuk 
melaksanakan pesan, membantu sasaran untuk belajar lebih banyak dan tepat, merangsang sasaran untuk meneruskan pesan yang diterima kepada orang lain, mempermudah memperoleh informasi oleh sasaran, mendorong keinginan orang untuk mengetahui, kemudian lebih mendalami dan akhirnya memberikan pengertian yang lebih baik, dan membantu menegakkan pengertian yang diperoleh.

Metode yang digunakan oleh BP3K dalam penyuluhan ini yaitu dengan menggunakan 2 metode yaitu metode penyuluhan perorangan dan metode kelompok. Penyuluhan perorangan Khusus untuk penyuluhan peternakan sapi petugas datang langsung kerumah atau lahan usaha petani sedangkan untuk kelompok dilaksanakan dirumah ketua kelompok tani atau dilahan petani/peternak, pada tahun 2013 telah dilakukan 2 kali penyuluhan terhadap 3 kelompok peternak petani, kelompok Kamangta, Prima dan Boga jaya. Penyampaian materi sebaiknya menggunakan metode dan media untuk mempermudah pemahaman dan untuk menarik perhatian sasaran.
Tenaga penyuluh di BP3K Kecamatan Sinonsayang merupakan tenaga lulusan setingkat D3. Para penyuluh bertujuan untuk menjadikan petani dari swadaya menjadi petani yang swakarsa. Hal ini sesuai dengan slogan BP3K Kecamatan Sinonsayang, yaitu penyuluhan dari petani, oleh petani dan untuk petani. Untuk itu, penyuluh BP3K selalu menindak lanjuti masalah yang dihadapi petani dengan mendiskusikannya pada saat kegiatan penyuluhan berlangsung serta juga membantu dengan langsung bertindak di lahan pemeliharaan ternak sapi potong milik petani.

Tenaga penyuluh BP3K Kecamatan Sinonsayang ada 5 orang, yang melakukan kegiatan penyuluhan pada 3 desa yang ada di kecamatan Sinonsayang, yaitu pada gabungan kelompok tani "Kamangta" di desa Blongko, gabungan kelopok tani "Prima" di desa Ongkaw II dan gabungan kelompok tani "Boga Jaya" di desa Ongkaw III.

Frekuensi penyuluhan merupakan frekuensi peternak dalam mengakses saluran komunikasi atau 
informasi mengenai teknologi yang dapat diterapkan dalam usaha ternak sapi. Efektivitas penyuluhan merupakan frekuensi peternak dalam mengikuti kegiatan penyuluhan serta perkumpulan kelompok tani, Frekuensi program penyuluhan dilihat dari banyaknya pertemuan dengan penyuluh. Adapun Frekuensi penyuluhan yang diikuti oleh peternak di Kecamatan Sinonsayang dapat dilihat pada Tabel 1.

Berdasarkan Tabel 1 menunjukkan frekuensi penyuluhan yang diikuti oleh peternak yang terdiri dari penyuluhan perorangan dan kelompok. Penyuluhan kelompok yang diikuti oleh responden terdiri dari kegiatan penyuluhan yang diadakan oleh penyuluh pertanian serta penyuluhan yang diadakan oleh BP3K di Kecamatan Sinonsayang.

Kegiatan penyuluhan maupun perkumpulan kelompok tani merupakan salah satu saluran untuk menyampaikan informasi pemeliharaan ternak sapi potong. Selain itu, dalam kegiatan penyuluhan dan kelompok tani, peternak saling berbagi mengenai permasalahan yang dihadapi dalam usaha tani ternak. Kegiatan penyuluhan dan kelompok tani dapat menambah pengetahuan peternak mengenai pemeliharaan ternak sapi potong. Frekuensi penyuluhan perorangan merupakan frekuensi peternak dalam mengakses informasi. Pemberian penyuluhan ini cara menyajikan program-program tentang peternakan sapi secara sederhana, para peternak menerima materi tidak menggunakan alat bantu juga alat peraga. Pengetahuan para peternak masih sangat kurang baik dalam beternak dan pada akhirnya mempengaruhi usaha ternak mereka. Dalam hal ini, sebaiknya semakin sering peternak mengikuti penyuluhan maka pengetahuannya tentang teknologi yang disampaikan semakin meningkat dan akhirnya dapat mempengaruhi peternak mengadopsi teknologi tersebut. Hal ini sesuai dengan pendapat Setyarini (2009), bahwa frekuensi penyuluhan mempengaruhi pengambilan keputusan seseorang.

Populasi ternak sapi yang dipelihara oleh 30 responden di desa Blongko, desa Ongkaw II dan desa Ongkaw III, bertambah yaitu 5 ekor sapi jantan dewasa dan 4 ekor anak 
sapi betina (pedet) jadi total populasi menjadi 9 ekor ternak sapi.

Jika dilihat dari pertambahan populasi sebanyak 9 ekor ternak sapi, maka dalam satu tahun peternak di desa Blongko, desa Ongkaw II dan desa Ongkaw III, mengalami ketambahan populasi sebesar 17,31\%. Pertambahan populasi ini bukan karena adanya penyuluhan dari BP3K tetapi sebelum penyuluhan populasi itu sudah bertambah diakibatkan adanya kelahiran 4 ekor anak sapi betina (pedet) dan bertambahnya karena dibeli 5 ekor sapi jantan dewasa, penyuluhan oleh BP3K yang dilakukan dampaknya hanya menambah pengetahuan petani/peternak dan tidak menambah populasi ternak. jumlah responden yang melakukan pertambahan tersebut hanya 10 responden atau $30 \%$ dari 30 responden dan 20 responden belum ada ketambahan ternak sapi.

\section{Kartasapoetra}

menyatakan penyuluh pertanian merupakan agen bagi perubahan perilaku petani, yaitu mendorong petani mengubah perilakunya agar sadar bahwa menjadi petani dengan kemampuan yang lebih baik dan mampu mengambil keputusan sendiri, yang selanjutnya akan memperoleh kehidupan yang lebih baik.

$$
\text { Pengetahuan peternak }
$$

merupakan pola pemikiran pemeliharaan ternak sapi yang kemudian melahirkan sikap dan pada gilirannya melahirkan perbuatan atau tindakan. Adanya wawasan peternak yang baik tentang suatu hal, akan mendorong terjadinya sikap yang pada gilirannnya mendorong terjadinya perubahan perilaku. Pengetahuan petani/peternak di kecamatan Sinonsayang dalam hal meningkatkan populasi ternak, menyangkut manajemen pemeliharaan, seleksi bibit, pakan, kandang, sistem perkawinan, kesehatan ternak, dan pemasarannya belum baik hal ini disebabkan karena kurangnya keingintahuan para petani/peternak cara memelihara ternak sapi yang baik untuk meningkatkan populasi. Para peternak di Kecamatan Sinonsayang memelihara ternak sapi masih dengan cara tradisional dan juga melakukan kawin alami. 
Menurut Wiriaatmadja (1990) bahwa, pengetahuan petani sangat membantu dan menunjang kemampuannya untuk mengadopsi teknologi dalam usahataninya dan kelanggengan usahataninya. Semakin tinggi tingkat pengetahuan petani maka kemampuannya dalam mengadopsi teknologi di bidang pertanian juga tinggi, dan sebaliknya.

\section{KESIMPULAN DAN SARAN}

Berdasarkan hasil penelitian maka dapat disimpulkan bahwa program penyuluhan yang dilakukan oleh BP3K belum maksimal sehingga kegiatan penyuluhan hanya dapat menjangkau sebagian kecil dari jumlah peternak. Peternak kurang motivasi berusaha akibatnya populasi ternak sapi kurang berkembang.

Perlu lebih diperhatikan lagi untuk lembaga penyuluh/instansi terkait dalam memberikan penyuluhan agar lebih baik sehingga dapat meningkatkan motivasi berusaha para peternak.

\section{DAFTAR PUSTAKA}

Effendy.2003. Diktat Monitoring dan Evaluasi APP Yogyakarta. (tidak diterbitkan).
Elly, F, H dan A. H.S. Salendu. 2012. Analisis Ekonomi Rumahtangga Peternak Sapi di Kecamatan Sinonsayang Kabupaten Minahasa. Jurnal Agribisnis dan Pembangunan Masyarakat (AGROPEM) ISSN: 208966700 Vol. 1, No. 1, Januari 2012. Manado+

Kartasapoetra. 1994. Efektivitas Penyuluhan pada peternakan Sapi Potong pada Dua Model Perkampungan. Tesis. Fakultas Pasca Sarjana. Institut Pertanian Bogor. Bogor.

Nawawi, H. 1995. Metode Penelitian Sosial. Gajah Mada University Press, Jakarta.

Notoatmodjo. 2007. Metode penyuluhan. Raja Grafindo Persada. Jakarta.

Setyarini, D. 2009. Skripsi Pengaruh Intensitas Penyuluhan terhadap Tingkat Partisipasi Masyarakat dalam Program Penghijauan Kota : Studi Kasus Kecamatan Kota Kabupaten Wajo. 
Universitas Indonesia,

Jakarta 